\title{
Employment status transitions and shifts in daily activity- travel behavior with special focus on shopping duration
}

\author{
Soora Rasouli ${ }^{1} \cdot$ Harry Timmermans ${ }^{1} \cdot$ Peter van der Waerden $^{1}$
}

Published online: 7 October 2015

(C) The Author(s) 2015. This article is published with open access at Springerlink.com

\begin{abstract}
Although there is a significant body of work associating socio-demographics with activity-travel behaviors, very few prior studies have examined the relationship between changes in employment status and adaptations in activity-travel patterns. To examine this issue, this study employs data of the Puget Sound Panel Survey, comprising a total of 7135 respondents. Through descriptive analyses and a random parameters panel effects regression model, we analyze changes in the time spent on shopping between two consecutive waves of the panel differentiating between employment status transitions, after controlling for a set of socio-demographic variables and day of the week. Results indicate that while activity-travel patterns in general and shopping duration in particular are relatively stable for the groups showing no transitions in employment status, the transition groups show evidence of a reorganization of their shopping activities across the week. In addition, results of the model indicate that the relationship between change in employment status and dynamics in shopping behavior is not symmetrical.
\end{abstract}

Keywords Employment status change $\cdot$ Panel data $\cdot$ Activity-travel behavior

\section{Introduction}

Recently, various authors (e.g. van der Waerden et al. 2003a, b) argued that critical incidents and lifecycle events may force or trigger individuals and households to reconsider the way they have organized their activities in time and space. Change in employment status constitutes a good example of such lifecycle events. Being employed means that work commitments more or less fix the location, activity type, duration, and start and end

Soora Rasouli

s.rasouli@tue.nl

1 Urban Planning Group, Eindhoven University of Technology, PO Box 513, 5600 MB Eindhoven, The Netherlands 
times of a considerable part of the day, which in turn may strongly influence the use of mobility resources. A transition to unemployment status implies that the released work time can be allocated to other activities, while in addition the flexibility in scheduling other activities increases. Vice versa, the transition from being unemployed to being employed reduces the flexibility in organizing activities in space and time and likely increases time pressure.

Insight into this dynamic relationship between change in employment status and changes in activity-travel patterns is of paramount importance to transportation planning. Shifts in the timing and amount of travel may substantially impact the use of transportation infrastructure and therefore congestion, emission and other related indicators of accessibility and quality of life. The relevance of the topic has been increased in recent years due to the economic crisis in many parts of the world. Using the Netherlands as an example, the discussion to further invest in highways and other transportation infrastructure or to invest in a better use of existing infrastructure has dominated transportation policy for many years. Since the recent economic crisis, however, there has been evidence of a reduction in traffic intensity on some main corridors. Moreover, it is well known that a small reduction in traffic volume tends to have magnified effects on congestion levels. Combined with the necessity of governments to reduce their spending, this recent trend has fuelled the discussion whether plans and programs to invest in new highways and upscaling of existing ones should at least be postponed. While this shift in discussion is not void of opportunism, it nevertheless highlights the underlying questions about the nature and strength of the relationship between changes in employment status and shifts in activity-travel behavior. Although the direct effects of change in employment status on travel behavior are immediately clear, secondary and higher order effect are not, and as we know, ultimately these higher order effects determine the consequences of changes in employment status on the urban and transportation system.

Surprisingly, an examination of the transportation literature shows that little is known about shifts in activity-travel patterns that are triggered by changes in employment status. One reason may be the lack of panel data. Some studies have included employment status as an explanatory variable in cross-sectional analysis. For example, Lau (2006) found in a study in Hong Kong that non-employed respondents exhibited different behavior in coping with limited accessibility. In addition to the tendency of having fewer children and not living with their elderly parents, more frequent walking to non-work activities and living in urban areas were commonly used strategies. In a study on lifestyle classification, Lin et al. (2009) identified a segment, which they called home-centered persons. Respondents belonging to this segment have a lifestyle that involves relatively few activities and travel outside. As this segment has the second highest unemployment rate, it suggests that unemployed people are less mobile. Unfortunately, their study cannot rule out other explanations as they also found that this segment has the largest share of students. Moreover, they found the highest unemployment rate is strongly correlated with another lifestyle segment, characterized by active participation in many discretionary activities. Thus, limitations in their analysis, especially the lack of any interactions between sociodemographics variables, prevent drawing any strong conclusions regarding the relationship between employment status and activity-travel behavior.

To examine this topic, we analyzed the Puget Sound Panel Survey. The use of a panel seems warranted because it allows an examination of aspects of activity-travel behavior before and after transitions in employed status. Although the findings pertain to this specific region in the USA, the findings may have wider validity beyond the Puget Sound 
area since they impinge on broader discussions of the effects of non-employment on travel behavior and the most appropriate policies to reduce congestion and improve accessibility.

More specifically, we analyzed changes in time allocation for different transitions in employment status, controlling for a set of socio-economic variables, using econometric models. A random parameters panel effects regression model of changes in time allocation for different activities was estimated as a function of these variables. The paper reports the results for shopping duration. Before presenting the results of this analysis, we first discuss the conceptual considerations underlying the analysis. Next, we discuss the data that were used for the analysis, focusing on sample characteristics and some features of the data that led to specific operational decisions in model estimations. The paper is completed with a discussion of the implications of the estimation results.

\section{Conceptual considerations}

This study is positioned in the overlap of activity-based analysis of travel behavior and life trajectory studies. According to the activity-based analysis framework, travel should be viewed as a result of demand, induced by the fact that individuals have to be involved in activities and consequent travel in their pursuit of realizing particular needs and desires. In order to satisfy these needs and achieve associated aspirations (targets), they need to conduct particular activities. The realization of particular needs may require (formal) commitments. For example, in order to generate income, individuals need to become involved in work activities. Work arrangements tend to be institutionalized, implying that individuals sign formal work contracts, inducing commitments and (semi-)formal start and end times of work activities for particular days of the week and weeks of the year. Institutionalized commitments tend to have a certain fixed duration. Although the choice to become involved in work activities is in principle a discretionary choice, institutionalized work arrangements and commitments subsequently constrain the timing and flexibility of involvement in non-work activities.

Because the supply of facilities allowing individuals to conduct activities is distributed across space, the decision to participate in activities logically implies (induced) travel. In more general terms, individuals face the problem how to organize their activities in time and space, subject to varying degrees of flexibility in deciding on the timing, duration, and location to conduct these activities and various types of locational, temporal, spatio-temporal and institutional constraints such as to satisfy their needs and concomitant aspirations. We assume that individuals learn about the opportunities and constraints in their environment by personal experience (i.e. their activity-travel behavior) and several external information sources. They build up particular beliefs about the state of the environment, act upon these and experience the positive and negative consequences of their decisions. Through learning, updating of beliefs, and exploration, they develop certain routines, scripts and habits that produce perhaps not optimal, but certainty satisfactory behavior that meets their constraints and is congruent with their aspirations, conditional on the constraints they face. Such behavior may be context-dependent. Over time, individuals develop a repertoire of context-dependent routine-like, habitual activity-travel patterns. This reasoning articulates the complex, context-dependent, interdependencies between activity participation, timing and duration, location choice and transportation mode choice decisions, subject to individual, household, institutional and spatio-temporal constraints, that generate observed activity-travel patterns. Developments in activity-based modelling 
(see Rasouli and Timmermans 2014 for a recent review) can be viewed as alternative ways of (partly) modelling these interdependencies.

Although this framework implies that under quasi-stationary conditions, individuals will develop habitual patterns over time, leading to a system in equilibrium, in reality constraints may change, individual may change their needs and aspirations levels and in addition the state of the system may change either exogenously or endogenously due to the accumulated decisions of individuals. In turn, such change may trigger individuals to reconsider and perhaps adjust their habitual repertoire of activity-travel behavior. Of particular relevance for the present study are changes induced by lifecycle events, such as marriage, birth of a child and the focus of the present study change in employment status. A limited set of previous studies has documented the influence of lifecycle events on changes in activity-travel patterns. Examples include Lanzendorf (2003, 2010), Prillwitz et al. (2006, 2007), Verhoeven et al. (2006), Levinson (2009), and Oakil et al. (2011).

Take the transition from being employed to the state of unemployment as an example. The shift from employment to unemployment means less income. Consequently, the individual needs to decide how to compensate for this loss of income. Adaptation to this new situation may involve participating less in activities, spending less on (particular) activities, traveling less frequently, shifting to less costly transportation modes, visiting less distant locations or travel more efficiently by increasing trip chaining, using savings or some combination of these strategies. At the same time, however, the transition to unemployment also implies that the work time is released, triggering the individual to decide how to use this extra time and to consider rescheduling the remaining activities, as prior constraints may no longer hold. Thus, the shift to unemployment enforces or intensifies resource constraints but simultaneously reduces the influence of spatio-temporal constraints and time pressure due to work commitments.

Vice versa, the transition from unemployment to employment induces increasing demands on the activity agenda in the sense that the individual is expected to show up for work, most likely at a particular location and at particular times, depending on the flexibility of the work arrangement. It will also increase the time for the commuter trip. However, a new job will also come with additional income, which can be spend on additional resources, such as a (second) car, and on increased expenditures for activities and travel. The reduction in available time for non-work activities should be compensated in some way. Individuals may consider participating (less) in non-work activities, spending less time on the activities in which they participate, shift activities to other days of the week, choose faster transportation modes, increase the amount of trip chaining or some combination of these. In principle, more complex adaptation strategies some of which are beyond the individual might be considered, such as multi-tasking, (de-) fragmentation of time, task re-allocation within the household, family, social network or hiring help. As these strategies are not considered in the present study, we will not elaborate here on their potential relevance and impact.

\section{The data}

Data were taken from the Puget Sound Transportation Pane. It is the first general-purpose travel panel survey in an urban area in the United States. The panel is composed of approximately 1700 households in the four county central Puget Sound region (King, 
Kitsap, Pierce and Snohomish counties). It records all trips during two consecutive days of all household members. The data cover 10 waves from 1989 to 2002 .

The current analysis is based on observations of two-day activity-travel patterns of 7135 individuals, after filtering out students, Individuals participate in multiple waves. Table 1 gives an overview of sample characteristics. It shows that the sample has an approximately equal share of men and women. The percentage of the age categories monotonically decreases with increasing age. The distribution of occupation varies, although the share "unknown" is high. The number of responses and reporting diary for weekends is very few.

The dataset was disaggregated by employment status in the different waves. By comparing employment status between consecutive waves, transitions in employment status could be derived. Logically, individuals can keep their employment status (employed or unemployed) or may shift their status (from employed to unemployed, or vice versa). Table 2 gives an overview of transitions. Note that this procedure does not capture any transitions that have occurred in between two successive waves, but these probably do not significantly affect activity-travel patterns. On the other hand, although the employment status may not change, people may change the location of their job, which in turn may dramatically influence their activity travel patterns. Therefore, such respondents were

Table 1 Sample characteristics

\begin{tabular}{llcc}
\hline Characteristics & Levels & Frequency & Percentage \\
\hline Gender & Male & 3402 & 47.7 \\
& Female & 3733 & 52.3 \\
Age & Younger than 35 years & 2631 & 36.9 \\
& 35-55 years & 3173 & 43.6 \\
& Older than 55 years & 1379 & 19.3 \\
& Unknown & 12 & 0.2 \\
Occupation & Professional/technical & 1632 & 22.9 \\
& Manager/admin./business owner & 755 & 10.6 \\
& Craftsman or foreman & 445 & 6.2 \\
& Service workers & 456 & 6.4 \\
& Other & 1660 & 23.2 \\
Total & Not applicable/refused & 2187 & 30.7 \\
\hline
\end{tabular}

\footnotetext{
${ }^{a}$ Secretary/clerical. Retail sales, shop/production worker, general labor
}

Table 2 Overview of transitions

\begin{tabular}{lcc}
\hline Transition & Frequency & Percentage \\
\hline Employed $\rightarrow$ Employed & 12,854 & 62.2 \\
Employed $\rightarrow$ Unemployed & 983 & 4.8 \\
Unemployed $\rightarrow$ Employed & 711 & 3.4 \\
Unemployed $\rightarrow$ Unemployed & 6128 & 29.6 \\
Total number of transitions & 20,676 & 100.0 \\
\hline
\end{tabular}


deleted from the sample that was used for analysis and model estimation. It creates more pure contrasts between the employment status groups.

Table 2 gives an overview of transitions in employment status. The total number of transitions in the sample is 20,676. Of these, $62.2 \%$ stays employed between two consecutive waves. Another 29.6 per cent keeps their unemployed status. Interesting for our analysis is the remaining $8.2 \%$. The transitions from employed to unemployed equal $4.8 \%$, whereas the reverse transition amounts to $3.4 \%$.

\section{Analyses and results}

In this paper, we report the results of descriptive analyses and the estimates of a random parameters panel effects regression model of change in time allocation to shopping between two successive waves. A full descriptive analysis, guided by the adopted activitybased framework which articulates the interdependencies between different facets of activity-travel patterns, would include participation rates, time expenditures on different types of activities, classified into mandatory and discretionary activities, travel time by activity type, travel distance by activity type, total activity time and travel distance for respectively work and non-work activities and choice of transportation mode for different activity types. Due to space limitations, we restrict reporting the results of these analyses to changes in total travel time and in travel time by activity, and to changes in total activity duration and activity duration by activity.

The model generalizes these descriptive analyses by regressing the various transitions in employment status on changes in activity duration to several activity types, after controlling for a set of socio-demographic variables and day of the week. The paper reports the results for shopping.

\section{Descriptive analysis}

A first analysis is the change in average travel time for different activities. Table 3 shows that average travel time drops for almost all trip purposes/activities after respondents have become unemployed. The exception is for school and college, which may suggest that former workers have decided to start taking lessons to increase their job opportunities and/ or escort their children more often to school. Comparing these results for the results pertaining to the employed-employed category (quo status) suggests that respondents who became unemployed are conducting some activities closer to home compared to the employed respondents.

The pattern for the reverse transition (from unemployed status to employment status) is more interesting. As expected, average travel time for work increases. The reduced time budget due to work commitments has to be compensated in part by spending less time on travel and the execution of other activities. Table 3 demonstrates that such reduction is not the same for all trip purposes. School is not affected. It seems that travel times related to the conduct of personal activities and appointments even slightly increase which may be due to work, while shopping and free time are considerably more affected. These findings are in line with the findings mentioned in the literature review. It seems that being employed triggers participating in some personal and social activities, leading to more 
Table 3 Average travel time before and after transition (min)

\begin{tabular}{|c|c|c|c|c|c|c|}
\hline \multirow[t]{2}{*}{ Trip purpose } & \multicolumn{3}{|c|}{ Transition 1} & \multicolumn{3}{|c|}{ Transition 2} \\
\hline & $\begin{array}{l}\text { Empl- } \\
\text { Unempl }\end{array}$ & $\begin{array}{l}\text { Empl- } \\
\text { Empl }\end{array}$ & $\begin{array}{l}t \text { test* } \\
\text { significance }\end{array}$ & $\begin{array}{l}\text { Unempl- } \\
\text { Empl }\end{array}$ & $\begin{array}{l}\text { Unempl- } \\
\text { Unempl }\end{array}$ & $\begin{array}{l}\mathrm{t} \text {-test }{ }^{\mathrm{a}} \\
\text { significance }\end{array}$ \\
\hline Work & -10.11 & -4.52 & 0.000 & 6.15 & 0.68 & 0.000 \\
\hline Shopping & -0.08 & -0.98 & 0.028 & -3.19 & -2.03 & 0.037 \\
\hline School & 1.78 & 0.68 & 0.013 & 0.24 & 1.61 & 0.011 \\
\hline Visiting & -0.30 & -0.25 & 0.916 & -0.56 & -0.08 & 0.330 \\
\hline Free time & -0.85 & -1.15 & 0.595 & -2.77 & -1.59 & 0.133 \\
\hline Personal & -3.59 & 0.00 & 0.000 & -2.67 & -2.02 & 0.430 \\
\hline Appointment & 2.03 & 3.60 & 0.092 & 4.37 & 2.80 & 0.216 \\
\hline College & 0.03 & -0.07 & 0.047 & -0.03 & -0.00 & 0.769 \\
\hline Total & -11.07 & -2.69 & & 51.06 & -0.63 & \\
\hline $\mathrm{N}$ & 983 & 12,854 & & 711 & 6128 & \\
\hline
\end{tabular}

${ }^{a}$ Independent samples t-test

Table 4 Average activity duration differences for two transitions (minutes)

\begin{tabular}{|c|c|c|c|c|c|c|}
\hline \multirow{2}{*}{ Trip purpose } & \multicolumn{3}{|c|}{ Transition 1} & \multicolumn{3}{|c|}{ Transition 2} \\
\hline & $\begin{array}{l}\text { Empl- } \\
\text { Unempl }\end{array}$ & $\begin{array}{l}\text { Empl- } \\
\text { Empl }\end{array}$ & $\begin{array}{l}\mathrm{t} \text {-test }{ }^{\mathrm{a}} \\
\text { significance }\end{array}$ & $\begin{array}{l}\text { Unempl- } \\
\text { Empl }\end{array}$ & $\begin{array}{l}\text { Unempl- } \\
\text { Unempl }\end{array}$ & $\begin{array}{l}\mathrm{t} \text {-test }{ }^{\mathrm{a}} \\
\text { significance }\end{array}$ \\
\hline Work & -156.94 & -65.39 & 0.000 & 90.59 & -0.13 & 0.000 \\
\hline Shopping & 1.38 & -2.50 & 0.001 & -7.51 & -5.93 & 0.267 \\
\hline School & 10.02 & 2.82 & 0.000 & 2.43 & 7.13 & 0.026 \\
\hline Visiting & 1.15 & -0.90 & 0.166 & -6.13 & -0.52 & 0.004 \\
\hline Free time & 0.46 & -5.10 & 0.011 & -13.85 & -0.65 & 0.022 \\
\hline Personal & -14.53 & 1.72 & 0.000 & -0.03 & -3.96 & 0.143 \\
\hline Appointment & 37.90 & 55.20 & 0.001 & 90.19 & 58.38 & 0.000 \\
\hline Home & 4.89 & -9.99 & 0.000 & -31.05 & -14.38 & 0.002 \\
\hline College & 0.29 & -0.44 & 0.016 & -0.25 & -0.06 & 0.672 \\
\hline Total & -115.36 & -23.79 & & 124.43 & 32.88 & \\
\hline $\mathrm{N}$ & 983 & 12,854 & & 711 & 6128 & \\
\hline
\end{tabular}

\footnotetext{
${ }^{a}$ Independent samples t-test
}

appointments, further away from home. In turn, the extra time for these activities furthers reduces the time budget for other activities such as shopping.

Table 4 lists the changes in activity duration associated with a transition in employment status. Respondents in the panel who became unemployed reported a strong reduction in time expenditure to work, although the average time reported is still $40 \mathrm{~min}$ per day. Time expenditure to several other activities also slightly dropped. In contrast, these respondents increased their time expenditure to school and college. In case of a transition from unemployed to employed, time spent on work substantially increased. Coinciding with this shift in time allocation, time spent on school and college decreased, as did the amount of 
free time and time spent on visiting. Interestingly, time allocated to personal activities increased, which suggests that being employed increases time spent on personal commitments.

\section{Model specification and results}

Our prime interest is to examine the effect of transitions in employment status on time allocation to different activities. Panel data are the best kind of data for such analysis. However, every data set, including panel data, has its specific peculiarities, the effect of which should be minimized.

The model specification was therefore based on the following considerations. First, because the interest is to examine to what extent the four different classes that stem from the sequence of employment status in subsequent waves, a comparison against the mean is most revealing. Consequently, all explanatory variables in the model were effect coded to ensure that the estimated parameters have a direct meaning in this context. Second, an accurate assessment of the effects of employment status transitions necessitates controlling for the effects of other potentially influencing variables. Regardless of employment status transition, the literature on activity-based analyses has shown that the demand for different activities is a function of socio-demographic variables. Moreover, time expenditure on different activities tends to vary between days of the week. Finally, general trends in society may affect the dynamics of time allocation.

To include these considerations in the model specification, we focused the analysis on differences in time expenditure between different waves for particular activities. Because trends in society may impact all individuals, we included the four possible transition states as the main independent variable in the model. Effect coding was used to represent these transitions. It means that changes in time expenditure can be compared between the four different transitions against the mean. Because observations of activity-travel behavior may involve different days of the week, we controlled for day of the week in the model. Respondents completed an activity-travel diary for two consecutive days. Thus, days of the weeks could only be controlled for the block of 2 days. Differences in time expenditure may reflect differences in days of reporting between successive waves. However, because the vast majority of the panel reported their activity-travel behavior for the same block of two consecutive days, days of the weeks was included once in the model specification. Considering the possibility that being unemployed may have a lagged effect, the years of unemployment was introduced as an interaction with the transition Unemployed $\rightarrow$ Employed (years).

Similarly, a set of socio-economic variables was included to pick up any change in time expenditure triggered by transitions in these variables between consecutive waves. Because in addition to these observed characteristics, unobserved heterogeneity may affect the observations, a panel effect was estimated. Finally, to allow heterogeneity in behavioral response, random parameters were estimated.

Technically, for each activity $a$, a random parameters, panel effect regression model was estimated. It may be expressed as follows:

$$
\psi \Delta y_{i a}^{k \rightarrow k+1}=\boldsymbol{\gamma} \boldsymbol{\delta}_{i}^{k \rightarrow k+1}+\boldsymbol{\beta} \boldsymbol{S}_{\boldsymbol{i}}+\boldsymbol{\alpha} \boldsymbol{W}_{\boldsymbol{a}}+\phi(\boldsymbol{\delta} \otimes \boldsymbol{S})+\boldsymbol{\vartheta}(\boldsymbol{\delta} \otimes \boldsymbol{W})+\tau \boldsymbol{L}^{k \rightarrow k+1}+\boldsymbol{\varepsilon}_{i a}^{k \rightarrow k+1}
$$

where $\left(\Delta y_{i a}^{k \rightarrow k+1}\right)$ is the difference between the time that is spent on activity $a$ by individual $i$ from wave $k$ to wave $k+1, \delta$ is a vector of indicator variables representing transitions in employment status from wave $k$ to wave $k+1$ of individual $i, \gamma$ is a vector of marginal 
effects of transitions in employment status on changes in time spent on the considered activity, $\boldsymbol{\beta}$ is a vector of marginal effects of a vector of social demographic variables $\boldsymbol{S}_{\boldsymbol{i}}$ of individual $\boldsymbol{i}, \boldsymbol{\alpha}$ is a vector of marginal effects of day of the week $\boldsymbol{W}_{\boldsymbol{a}}$ for doing activity $a, \varphi$ is a vector of marginal effects of interactions between socio-demographic profiles and transition in employment status. $\boldsymbol{\vartheta}$ a vector of marginal effects of interactions between day of the week when activity $a$ is conducted and transition in employment status, $\left(L^{k \rightarrow k+1}\right)$ is equal to the length of unemployment if the transition is from unemployed to employed and zero otherwise, $\tau$ is the corresponding parameter, and $\otimes$ is the Kronecker product.

The parameter vectors are assumed independently and identically normal distributed:

$$
\begin{array}{ll}
\boldsymbol{\gamma} \sim N\left(0, \boldsymbol{\sigma}_{\gamma}^{2}\right) \rightarrow \boldsymbol{\delta}=\overline{\boldsymbol{\delta}}+\boldsymbol{\sigma}_{\gamma}^{2} \otimes \boldsymbol{\varepsilon}_{i a} & \boldsymbol{\varepsilon}_{i a} N(0, \boldsymbol{I}) \\
\boldsymbol{\beta} \sim N\left(0, \boldsymbol{\sigma}_{\boldsymbol{\beta}}^{2}\right) \rightarrow \boldsymbol{\beta}=\overline{\boldsymbol{\beta}}+\boldsymbol{\sigma}_{\boldsymbol{\beta}}^{2} \otimes \tau_{i a} & \tau_{i a} N(0, \boldsymbol{I}) \\
\boldsymbol{\alpha} \sim N\left(0, \boldsymbol{\sigma}_{\boldsymbol{\alpha}}^{2}\right) \rightarrow \boldsymbol{\alpha}=\overline{\boldsymbol{\alpha}}+\boldsymbol{\sigma}_{\boldsymbol{\alpha}}^{2} \otimes \boldsymbol{\omega}_{i a} & \boldsymbol{\omega}_{i a} N(0, \boldsymbol{I})
\end{array}
$$

Maximum likelihood estimation was used to estimate the model. Results for the shopping activity are listed in Table 5. Shopping was selected for this formal analysis because the results of the descriptive analysis indicated it represents an interesting activity category. Except for grocery shopping, shopping is a discretionary activity, implying that individuals and households have more flexibility deciding how much time to spend on shopping.

Table 5 shows that the estimated constant is -3.62 , which indicates that on average time expenditure to shopping during the 2 days of observation between two consecutive waves of the panel has decreased with around 4 min per day. Here, it should be noted that the panel data do not show any shift in participation in shopping activities beyond the 2 days of observation. For example, we cannot rule out that some of the respondents due to a change in employment status shifted their shopping from weekdays to weekends.

Both employment transition categories significantly deviate from the sample average. The positive sign of the estimated effect for a shift from employed to unemployed suggests that, keeping every else constant, respondents belonging to this category on average have increased the time they spend on shopping with almost 8 min between two consecutive waves of the panel survey.

Because many previous studies have provided strong evidence of gender differences in shopping participation and duration, gender was included as another explanatory variable in the model. To include the possibility of gender differences related to the employment status transitions, both main effects and interaction effects between gender and transition categories were estimated. Neither the main effects nor the interaction effects are statistically significant at conventional levels. It provides further evidence of the contention that changes in time allocation to shopping between two consecutive ways of the panel are primarily driven by shifts in employment status transitions. The effect of gender, both generally and for the specific transitions categories, remains relatively constant. Similarly, Table 5 shows that the main effects of occupation categories are not significant at the five per cent probability level.

The literature on activity-travel analysis has found evidence for the existence of day of the week preferences for conducting particular activities. Day of the week was therefore included in the model. Because each respondent provided activity-travel diary data for two consecutive days, while very few observations were recorded for weekend, only four 
Table 5 Parameter estimates

\begin{tabular}{|c|c|c|c|}
\hline Attribute & Levels & Mean & Standard erro \\
\hline Constant & & $-3.6226^{* * *}$ & 1.2605 \\
\hline \multirow[t]{4}{*}{ Transition } & Employed $\rightarrow$ employed & 0.7057 & 1.3774 \\
\hline & Employed $\rightarrow$ unemployed & $7.7408^{* * *}$ & 1.6610 \\
\hline & Unemployed $\rightarrow$ employed & $-7.2653 * * *$ & 2.1765 \\
\hline & Unemployed $\rightarrow$ unemployed & -1.1812 & \\
\hline \multirow[t]{3}{*}{ Age } & Less than 35 years & -0.0961 & 0.5672 \\
\hline & Between 35 and 55 years & -0.0180 & 0.5003 \\
\hline & Older than 55 years & 0.1141 & \\
\hline \multirow[t]{2}{*}{ Gender } & Male & $0.9771^{*}$ & 0.5918 \\
\hline & Female & -0.9771 & \\
\hline \multirow[t]{4}{*}{ Occupation } & Professional & -0.1442 & 0.7953 \\
\hline & Managers & 0.5949 & 0.9277 \\
\hline & Services/craftsmen & -0.5377 & 0.8686 \\
\hline & Other & -0.0870 & \\
\hline \multirow[t]{4}{*}{ Day of the week } & Monday & 0.0852 & 0.7164 \\
\hline & Tuesday & -0.5189 & 0.7682 \\
\hline & Wednesday & -0.2295 & 0.7166 \\
\hline & Thursday & 0.6632 & \\
\hline \multirow[t]{12}{*}{ Interactions } & Empl $\rightarrow$ empl*Gender & -0.1744 & 0.6778 \\
\hline & Empl $\rightarrow$ unempl $^{*}$ Gender & -0.8956 & 0.8253 \\
\hline & Unempl $\rightarrow$ empl $^{*}$ Gender & 1.0994 & 1.1585 \\
\hline & Empl $\rightarrow$ empl*DayWk1 & -0.2326 & 0.8296 \\
\hline & Empl $\rightarrow$ unempl*DayWk1 & 1.4928 & 1.0843 \\
\hline & Unempl $\rightarrow$ empl*DayWk1 & -1.2719 & 1.4414 \\
\hline & Empl $\rightarrow$ empl*DayWk2 & 0.2148 & 0.8730 \\
\hline & Empl $\rightarrow$ unempl*DayWk2 & 1.2027 & 1.1822 \\
\hline & Unempl $\rightarrow$ emp1*DayWk2 & -2.0615 & 1.5535 \\
\hline & Empl $\rightarrow$ empl*DayWk3 & -0.00981 & 0.8397 \\
\hline & Empl $\rightarrow$ unempl*DayWk3 & $3.2813^{* * *}$ & 1.0173 \\
\hline & Unempl $\rightarrow$ empl*DayWk3 & $-3.7543 * * *$ & 1.3613 \\
\hline Sigma & & $31.9726 * * *$ & 0.0619 \\
\hline \multicolumn{4}{|l|}{ Scale factors } \\
\hline Constant & & 0.0085 & 0.3849 \\
\hline \multirow[t]{4}{*}{ Transtition } & Employed $\rightarrow$ employed & 0.0033 & 0.3805 \\
\hline & Employed $\rightarrow$ unemployed & 0.3098 & 0.4177 \\
\hline & Unemployed $\rightarrow$ employed & 0.0268 & 0.4645 \\
\hline & Unemployed $\rightarrow$ unemployed & & \\
\hline \multirow[t]{3}{*}{ Age } & Less than 35 years & 0.0645 & 0.4632 \\
\hline & Between 35 and 55 years & 0.0009 & 0.4223 \\
\hline & Older than 55 years & & \\
\hline \multirow[t]{2}{*}{ Gender } & Male & 0.0003 & 0.3848 \\
\hline & Female & & \\
\hline
\end{tabular}


Table 5 continued

\begin{tabular}{llrc}
\hline Attribute & Levels & Mean & Standard error \\
\hline Occupation & Professional & 0.0044 & 0.3727 \\
& Managers & 0.0642 & 0.3870 \\
& Services/craftsmen & 0.0436 & 0.3822 \\
& Other & & 0.3760 \\
Day of the week & Monday & 0.0121 & 0.3770 \\
& Tuesday & 0.0485 & 0.3821 \\
& Wednesday & 0.0082 & 1.4489 \\
& Thursday & & \\
Estimation criteria & Unempl $\rightarrow$ empl*years of unempl & 0.8339 & \\
Constant only $(\mathrm{df}=2)$ & & $-100,052.7049$ & \\
Optimal (df $=50)$ & & $-100,005.5153$ & \\
\hline Years & & & \\
\hline
\end{tabular}

Years is years of unemployment

DayWk1 Monday, DayWk2 Tuesday, DayWk3 Wednesday

$* * *, * *, *$ Significance at $1,5,10 \%$ level

categories were distinguished. As before, both main and interaction effects were estimated to not rule out the possibility that different employment status transition groups have different day of the week preferences

Results indicate that the estimated interaction between the transition from unemployed to employed is significantly negative for Wednesday, while the transition from employed to unemployed is significantly positive for Wednesday. This suggests that time spent on shopping has changed significantly, particularly on the (working) days when the job status changed. It further emphasizes the interpretation that the transition to work status forces these individuals to reorganize their shopping activities across the days of the week.

The number of years in the unemployment state was included in the model to capture any possible effect of the period of unemployment on the difference in shopping activity time between the employment and unemployment state. As the results indicate, with increasing duration of unemployment, the difference in time spent on shopping increases when people get employed.

In general, the insignificant coefficients for many attributes, except employment status change, gender and interaction of some other attributes with employment status changes suggests that socio-demographic characteristics and day of the week per se do not have a strong influence on changes in shopping duration from one wave to the other, but that rather changes in employment status are the main impetus for changing shopping behavior.

As indicated, the random parameters panel effects regression model also estimates a distribution of effects, assuming a normal distribution. Table 5, however, illustrates that none of the estimated scale parameters is significant at the 5 per cent confidence level. It indicates that the sample is quite homogeneous in terms of changes in time allocated to shopping after controlling for the selected socio-demographic variables and days of the week. 


\section{Discussion}

Although the particulars of transportation policy show substantial differences between countries, countries such as the Netherlands face the issue of deciding between the right mixture of investing in new infrastructure or investing in better usage of existing capacity. In the current era of economic decline, this issue has become even more pertinent in the sense that the cost-benefit ratio may shift due to less intensive use of existing infrastructure as a result of increased unemployment, with proportionally higher effects on reduction of congestion levels, emissions and exposure, and the co-occurring need to cut government expenditures. Because the impact of increased unemployment is not immediately clear as individuals have fewer resources to allocate, but at the same time more flexibility in participating in activities, leading to additional travel, the combined effects of these countervailing factors are not obvious. The present study was conducted to examine in more detail this emerging topic. An examination of the literature indicated this is one of the few studies examining the impact of shifts in employment status on time expenditures related to other activities in general and shopping duration in particular.

The study is part of an overarching line of research in our group to better understand the dynamics of activity-travel patterns at varying time horizons, and develop a model of the dynamics of activity travel patterns. This study, using the Puget Sound panel survey, had led to the following conclusions. First, transitions in employment status induce changes in activity-travel behavior, reflecting the fact that individuals need to adjust their daily routines to cope with the challenges of the new situation. Results for shopping duration were reported in this paper. Second, adjustment in duration of activities reflects differences in underlying needs, strength of existing commitments, aspiration levels and the flexibility in habitual repertoires of activity-travel patterns. Finally, the reverse transitions from employed to unemployed and vice versa do not generate corresponding reverse processes of adaptation.

Although the present study has given rise to interesting and relevant conclusions, some limitations of the study should be explicitly mentioned. Some of these were unavoidable, given the available data. Others should lead to additional future research. First, it should be realized that the descriptive results and estimated coefficients of the model directly depend on the timing of the measurements as reflected in the waves. Coefficients will not be scalable to different temporal resolution. Second, and related to the first limitation, adaptation processes may operate at different temporal scales. Use of more continuous data, or perhaps retrospective surveys, would allow a more precise identification of the underlying adaptation processes. Third, we have not addressed in much detail any spatial variation but rather assumed that adaptation processes were spatially invariant. Future research should investigate spatial dependency in adaptation processes in more detail. Although we feel that very precise accessibility measures such as the logsum may behaviorally not be very valid, individuals may apply notions of action spaces and acceptable travel times to search for a job and conduct their activities. Thus, adaptation processes after controlling for socio-demographics may depend on the opportunities and constraints offered by different neighborhoods and parts of the metropolitan area. Future research should address this issue of spatial heterogeneity in adaptation processes.

Acknowledgments The authors would like to express their gratitude for receiving access to the Puget Sound Panel Data. Any errors are the sole responsibility of the authors.

Open Access This article is distributed under the terms of the Creative Commons Attribution 4.0 International License (http://creativecommons.org/licenses/by/4.0/), which permits unrestricted use, distribution, and reproduction in any medium, provided you give appropriate credit to the original author(s) and the source, provide a link to the Creative Commons license, and indicate if changes were made. 


\section{References}

Lanzendorf, M.: Mobility biographies. A new perspective for understanding travel behaviour. In: 10th International Conference on Travel Behavior Research, Lucerne (2003)

Lanzendorf, M.: Key events and their effect on mobility biographies: the case of childbirth. Int. J. Sust. Transp. 4, 272-292 (2010)

Lau, J.C.Y.: Accessibility and the coping behavior of the non-employed people in Hong Kong. Habitat Int. 30, 1047-1055 (2006)

Levinson, D.: Space, money, life-cycle, and the allocation of time. Transportation 26, 141-171 (2009)

Lin, H.-Z., Lo, H.-P., Chen, X.-J.: Lifestyle classifications with and without activity-travel patterns. Transp. Res. A 43, 626-638 (2009)

Oakil, A., Ettema, D., Arentze, T.A., Timmermans, H.J.P.: Dynamics in car ownership and life-cycle events: a longitudinal analysis. In: Proceedings of 90th Annual Meeting of the transportation research board, Washington, DC (2011)

Prillwitz, J., Harms, S., Lanzendorf, M.: Impact of life-course events on car ownership. Transp. Res. Rec. 1985, 71-77 (2006)

Prillwitz, J., Lanzendorf, M.: Interactions between residential relocations, life course events, and daily commuting distances. Transp. Res. Rec. 2021, 64-69 (2007)

Rasouli, S., Timmermans, H.J.P.: Activity-based models of travel demand: promises, progress and prospects. Int. J. Urb. Sci. 18, 31-60 (2014)

van der Waerden, P.J.H.J., Borgers A.W.J., Timmermans, H.J.P.: Key events and critical incidents influencing transport mode choice switching behavior: an exploratory study. In: Proceedings of 82nd Annual Meeting at the Transportation Research Board, Washington, DC (2003)

van der Waerden, P.J.H.J., Borgers, A.W.J., Timmermans, H.J.P.: The influence of key events and critical incidents on transport mode choice switching behavior: a descriptive analysis. Proceedings of IATBR Conference, Lucerne (2003)

Verhoeven, M., Arentze, T.A., Timmermans, H.J.P., van der Waerden, P.J.H.J.: Modeling the influence of structural lifecycle events on activity travel decisions using a structure learning algorithm. In: Proceedings of 11th International Conference on Travel Behavior Research Elsevier, Amsterdam (2006)

Soora Rasouli is Assistant Professor of the Urban Planning Group of the Eindhoven University of Technology, the Netherlands. She has research interests in activity-based models of travel demand, modeling of choice processes under uncertainty and spatial analysis. She is a member of the editorial board of Journal of Urban Planning and Development, International of Transportation, Modern Traffic and Transportation Engineering Research, International Journal of Urban Science, Journal of Traffic and Transportation Planning and JRCS. She is junior career member of the ISCTSC Board of the International Steering Committee for Travel Survey Conferences, and member of the TRB Special Committee on Travel Forecasting Resources. She has acted as guest editor for Environment and Planning B, Travel Behavior and Society, and the Journal of Choice Modelling.

Harry Timmermans is Head of the Urban Planning Group of the Eindhoven University of Technology, the Netherlands. He has research interests in modeling decision-making processes and decision support systems in a variety of application domains, including transportation. He is editor of the Journal of Retailing and Consumer Services, and serves on the board of several other journals in transportation, geography, urban planning, marketing, artificial intelligence and other disciplines. He is Co-chair of the International Association of Travel Behavior Research (IATBR), and member of several scientific committees of the Transportation Research Board. He has also served as member of conference committees in transportation an artificial intelligence.

Peter van der Waerden After finishing the education of Transportation Engineer at the National Academy of Transportation in Tilburg, Peter started in 1986 his academic career at the Urban Planning Group of Eindhoven University of Technology. In 1988, he received the academic degree in Human Geography at the Utrecht State University in Utrecht. Peter presented the results of many transportation related studies in various journals and at international conferences. In October 2012, Peter received the doctoral degree for the development of a parking analysis model for the prediction of effects in local areas. 